Pierre A. Casthely MD, John Dluzneski MD, Marilyn A. Resurreccion MD, Nikitas Kleopoulos MD, Vladimir Redko MD

\title{
Ventricular fibrilla- tion during general anaesthesia in a seven-year-old patient with mitral valve prolapse
}

\begin{abstract}
A case report is presented of a seven-year-old boy who developed ventricular fibrillation during general anaesthesia with atracurium, $\mathrm{O}_{2}, \mathrm{~N}_{2} \mathrm{O}$ and halothane, following tracheal intubation for hypospadias revision. He sponsaneousty defibrillated and the surgery was cancelled. Echocardiography done two days later was normal. The patient returned two weeks later for the same procedure. He developed nodal tachycardia, and premature ventricular contractions, which responded to lidocaine. A second echocardiographic examination done postoperatively while the child as crying showed mitral valve prolapse.
\end{abstract}

\section{Key words}

HEART: mitral valve prolapse; COMPLICATIONS: cardiac arrythmias.

From the Department of Anesthesiology, State University Hospital, Downstate Medical Center, Brooklyn, New York.

Address correspondence to: Dr. Pierre A. Casthely, Department of Anesthesiology, State University Hospital, Downstate Medical Center, 450 Clarkson Avenue, Box 6, Brooklyn, New York 11203.
Intraoperative arrhythmias occurs frequently during paediatric anaesthesia. Common causes include surgical stimulation under light anaesthesia, hypoxia and hypercarbia. We report an unusual case of ventricular fibrillation in a child during general anaesthesia, following tracheal intubation.

\section{Case report}

The patient was a seven-year-old white male scheduled for hypospadias revision. The initial hypospadia repair, two years previously under general anaesthesia had been without anaesthetic complications. The patient had no significant past medical history, no history of allergies, and currently was receiving no medications. Physical examination revealed a well developed boy with a blood pressure of $110 / 70 \mathrm{mmHg}$ and heart rate of 85 (regular), who was afebrile and weighed $26 \mathrm{~kg}$. The patient had normal first and second heart sounds with no murmurs, gallops, or rubs. The remainder of the physical examination was normal. Laboratory studies were within normal limits.

Since the patient was admitted on the day of surgery no premedication had been given. The patient was monitored with an EKG, a doppler for blood pressure measurement, and a precordial stethoscope. Mask induction with $\mathrm{O}_{2}, \mathrm{~N}_{2} \mathrm{O}$, and halothane was performed. A 20 gauge IV was then started and a rectal temperature probe inserted. The patient at this time was given $0.5 \mathrm{mg} \cdot \mathrm{kg}^{-1}$ atracurium to facilitate tracheal intubation. The EKG showed a normal sinus rhythm and there was minimal decrease of blood pressure. Just prior to laryngoscopy, however, the patient's EKG changed to a nodal rhythm with a rate of 74 , and occasional 
PVC's were noted. Halothane was discontinued at this time, but during laryngoscopy the patient went into ventricular bigeminy. A $6.5 \mathrm{~mm}$ uncuffed endotracheal tube (ETT) was inserted and bilateral breath sounds were noted. Immediately after ETT insertion, the patient developed ventricular fibrillation with no palpable blood pressure or carotid pulse. The patient's rectal temperture $\left(37.2^{\circ} \mathrm{C}\right)$ at this time was unchanged. A precordial thump was performed, followed by chest compressions and artificial ventilation. After approximately 30 seconds the patient spontaneously defibrillated and developed nodal bradycardia with a heart rate of 21 . This bradycardia converted to sinus rhythm (rate 100) after administration of $0.2 \mathrm{mg}$ of atropine. Arterial blood gases at this time were: $\mathrm{pH} 7.44$, $\mathrm{PCO}_{2} 25, \mathrm{PO}_{2} 569$. The surgery was cancelled and the patient was supported until the relaxant's effect had resolved, in about 45 minutes. The patient was then extubated without any reversal agent being given. There were no problems during emergence and the patient had normal mental status during the recovery room stay. He was discharged to the ward in normal sinus rhythm, with stable vital signs. An electrocardiogram done in the recovery room was normal.

The patient returned to the $\mathrm{OR}$ two weeks later for the same procedure. The preoperative workup, including normal echocardiography had shown no abnormality. For this anaesthetic the patient was premedicated with atropine $0.2 \mathrm{mg}$, meperidine $25 \mathrm{mg}$, and pentobarbitone $75 \mathrm{mg}$ all IM. Monitors used were an EKG, doppler pulse monitor, BP cuff and a precordial stethoscope. On arrival in the $O R$, a 20 gauge IV was started prior to induction. The patient was preoxygenated, and induced with fentanyl $2 \mu \mathrm{g} \cdot \mathrm{kg}^{-1}$, thiopentone $3 \mathrm{mg} \cdot \mathrm{kg}^{-1}$ and pancuronium $0.1 \mathrm{mg} \cdot \mathrm{kg}^{-1}$. Prior to laryngoscopy, the patient's rhythm convered to a fast nodal rhythm with a rate of between 110-120/minute. Lidocaine $1.5 \mathrm{mg} \cdot \mathrm{kg}^{-1}$ IV was given, which converted the patient back to sinus rhythm, before laryngoscopy. The patient was then intubated with a $6.5 \mathrm{~mm}$ uncuffed ETT and anaesthesia was maintained with $\mathrm{O}_{2}, \mathrm{~N}_{2} \mathrm{O}$, fentanyl and pancuronium.

Throughout the case the blood pressure remained in the range of $100-120 / 70 \mathrm{mmHg}$, the rectal temperature remained $37.2^{\circ} \mathrm{C}$. The EKG alternated between sinus and nodal rhythms at a rate of $100-110$. Because of the previous history of PVC's

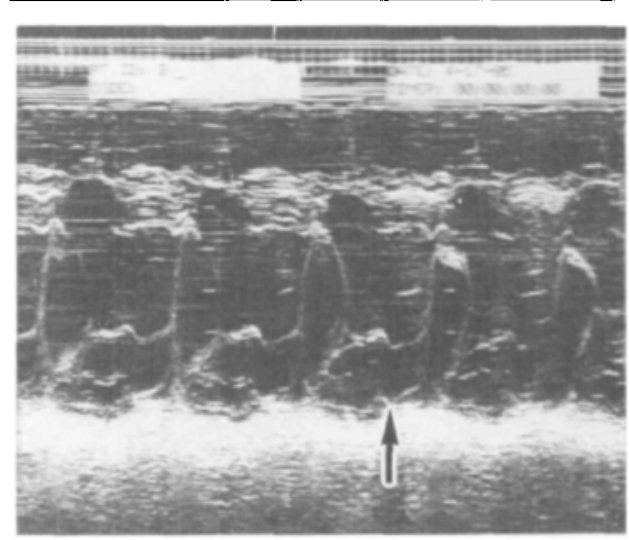

FIGURE Photograph of second echocardiographic examination of the patient laken under stressful conditions, showing prolapse of the mitral valve, as indicated by the arrow.

following nodal rhythm, it was decided to treat this rhythm with lidocaine and atropine even though blood pressure remained stable throughout. The patient was reversed with pyridostigmine 0.01 $\mathrm{mg} \cdot \mathrm{kg}^{-1}$ and edrophonium $0.5 \mathrm{mg} \cdot \mathrm{kg}^{-1}$ and extubated without difficulty at the end of the procedure. He continued to have occasional PVC's in the recovery room, which spontaneously disappeared six hours later. The patient had a second 2D echocardiography. The patient at this time was irritable and crying during the procedure. However, mitral valve prolapse was shown in the second echocardiography (Figure).

\section{Discussion}

Mitral valve prolapse is an abnormality of the mitral valve support structure that results in prolapse of the valve into the left atrium during contraction of the left ventricle. It is a common entity, occurring in 6-20 per cent of the adult population, with an incidence in children of 1.4 per cent. ${ }^{1}$

Mitral valve prolapse may be caused by myxomatous degeneration of the valve, elongation and thinning of the chordae tendinae, redundant and excessive valve tissue, or damage caused to the mitral valve in rheumatic carditis due to a dilated mitral annulus. ${ }^{2}$

Many patients with this disorder are asymptomatic, but others complain of fatigue, dyspnoea and chest pain, ranging from mild to incapacitating. 
Palpitations are noted in up to 50 per cent of patients with mitral prolapse and long-term monitoring has substantiated the frequent occurrence of arrhythmias. ${ }^{3}$ Arrhythmias can include the more common premature ventricular beats atrial premature beats, atrial or ventricular tachy dysrhythmias, and atrioventricular block. Physical findings on auscultation can include a mid-systolic click associated with a late systolic murmur, or an isolated late systolic murmur that can be increased by having the paticnt perform a Valsalva manoeuvre. Any manoeuvre which decreases cardiac volume tends to increase the mitral valve prolapse, thereby causing the click and the murmur to occur earlier in systole and thus prolonging the murmur. Conversely those manoeuvres that increase the cardiac volume tend to move the click and murmur later into systole. In approximately 70 per cent of patients, electrocardiography can show dysthythmias, a prolongation of the QT interval, T wave inversion, or ST segment changes. ${ }^{3}$ A definitive diagnosis is made with a combination of m-mode, $2 \mathrm{~d}$, and doppler echocardiography.

Optimal anaesthetic management of a patient with mitral valve prolapse requires that one should be aware of the hacmodynamic alterations brought about by induction and maintenance of anaesthesia. Drugs that may cause tachycardia, a reduction in peripheral vascular resistance, or a reduction in venous return enhance the redundancy of the mitral leaflets and can increase valve prolapse. Mitral valve prolapse itself brings about a fall in cardiac output and coronary perfusion, with possible precipitation of serious arrhythmias.

Atracurium in dose of $0.5 \mathrm{mg} \cdot \mathrm{kg}^{-1}$ may release histamine and produce hypotension. This hypotension, combined with the halothane effect on cardiac output, may have produced prolapse of the mitral valve in our patient, resulting in ventricular fibrillation. Another cause of the ventricular fibrillation could have been massive catecholamine discharge in the presence of light halothane anaesthesia. The dysrhythmias caused by the prolapsed leaflets may be enhanced further by increased catecholamine level, because an increased sensitivity to catecholamines is seen in patients with mitral valve prolapse. ${ }^{4}$ Halothane itself is well known to sensitize the heart to catecholamines.

This patient did not have a mid-systolic click on auscultation or any history of palpitation. Echocar- diography is usually the best diagnostic test available. The first echocardiographic examination was normal. Since the arrythmia persisted we were convinced that the diagnosis was missed and we requested a second echocardiographic examination. During a fairly stressful situation the mitral valve prolapsed. It is known that tachycardia can produce prolapse of the mitral valve.

Currently the most effective drug for control of atrial and ventricular dysrhythmias in mitral valve prolapse is propranolol. The expected response to an arrhythmia often does not occur in patients with mitral valve prolapse. For example, a bradyarrhythmia may be resistant to atropine and require isoproterenol or electrical pacing, while premature ventricular contractions are often refractory to lidocaine. $^{5}$

When one is faced with arrhythmias in the perioperative period and all the common causes have been excluded, MVP should be considered a possible diagnosis, particularly in young healthy adults and paediatric patients. Nevertheless, the vast majority of patients with mitral valve prolapse will have an uneventful anaesthetic course.

\section{Acknowledgement}

We thank Ms. Ellen L. Jackson for manuscript preparation.

\section{References}

1 Berry FA, Lake CL, Johns RA, Robers BM. Mitral valve prolapse - another cause of intraoperative dysarthythmias in the pediatric patient. Anesthesiology 1985; 62: 662 .

2 Thiagarajah $S$, Frost EAM. Anaesthetic considerations in patients with mitral valve prolapse. Anaesthesia $1983 ; 38: 560$.

3 Forbes $R B$, Morton $G H$. Ventricular fibrillation in a patient with unsuspected mitral valve prolapse and a prolonged Q-T interval. Can Anaesth Soc J 1979; $26: 424$.

4 Kowalski SE. Mitral valve prolapse. Can Anaesth Soc J 1985; 32: 138.

5 Krantz EM, Viljoen JF, Schermer R, Cañas, MS. Mitral valve prolapse. Anesth Analg 1980; 59: 379. 
Résumé

Un cas est rapporté d'un enfant âgé de sept ans présentant une fibrillation ventriculaire durant l'anesthésie générale avec atracurium, $\mathrm{O}_{2}, \mathrm{~N}_{2} \mathrm{O}$ et halothane suivi d'une intubation endotrachéale pour une revision d'hypospadias. Le patient s'est défibrilé spontanément et le cas fut annulé. Les $S M A_{6}$ avant et après l'épisode étaient normaux. L'échocardiographie faite deux jours plus tard était normal. Il retourna deux semaines plus tard pour la même procédure. Il développa une tachycardie nodale, une contraction ventriculaire prématurée qui répondit à la lidocaine. Les $S M A_{6}$ faites avant et aprés étaient aussi normaux. Une deuxième échocardiographie faite en période postopératoire alors que le patient pleurait a démontré un prolapsus de la valve mitrale. 